\title{
Effect of Genotype and Husbandry System on Blood Parameters, Oxidative and Native Immune Status: Welfare and Implications on Performance of Organic Laying Hens
}

\author{
Cecilia Mugnai ${ }^{1}$, Alessandro Dal Bosco ${ }^{*}$, Livia Moscati $^{2}$, Lorenzo Battistacci $^{2}$ and Cesare Castellini ${ }^{1}$ \\ ${ }^{I}$ Department of Applied Biology, Borgo XX giugno, 74 - 06121 Perugia, Italy \\ ${ }^{2}$ Istituto Zooprofilattico Sperimentale dell'Umbria e delle Marche, via Salvemini, 1 - 06121 Perugia, Italy
}

\begin{abstract}
The aim of the present work was to compare the effect of organic production $v s$ standard cage system on welfare and performance of a pure breed (Ancona) vs a commercial strain (Brown Hy-Line) of laying hens through a multifunctional approach (behaviour, tonic immobility, feathers score, antioxidant status of the body, blood parameters, innate immunity and mortality). The trial was carried out in farm of the Dpt. of Applied Biology (University of Perugia), where 17-weeks-old females of Ancona breed $(n=200)$ and Brown Hy-Line $(n=200)$ were divided in 2 homogenous groups of 100 birds each and assigned to cage or organic rearing systems.

The genotype of the hens affected in a degree which depends on rearing system almost all the variables. The feeding and resting activities were higher in caged whereas moving activities were higher in organic hens and especially in Ancona birds. Social relationships showed genotype and rearing system effects being higher in Brown Hy-Line hens particularly when reared in cage. The TI duration was affected by genotype and rearing system being the immobility time longer in Brown Hy-Line. The plumage condition showed a great rearing system effect and genotype effects was observed only between organic groups where Ancona hens showed the better feathers condition. Regarding native immune status serum bactericidal activity showed the highest values in organic hens and mainly in Ancona ones. On the contrary, lysozyme showed greater value in caged hens. The haptoglobin value was lower in organic Ancona group, the same hens showed about $30 \%$ greater reactive oxygen substances, but accompanied by highest the antioxidant power. Organic rearing system, mainly in the Ancona hens, induced the highest red blood cells, haemoglobin and hematocrite values. Lymphocytes were higher in Organic birds thus reducing the H/L ratio in Organic hens. As expected, organic birds showed the worst feed efficiency and percentage of deposition, but the lowest mortality rate. In conclusion, on the basis of all these information together with the low mortality rate, Ancona hens showed the better welfare status, mainly when they were organically reared.
\end{abstract}

Keywords: Laying hen welfare, genotype, rearing system.

\section{INTRODUCTION}

A correct assessment of animal welfare should involve multiple indicators such as behaviour, physiology, body injuries, disease and performance [1]. In recent years it has become evident that there is a strong correlation between animal behaviour, stress and the neuro-endocrine and immune systems [2-4]. Therefore, unfavourable environmental conditions could lowered homeostatic functions, such as the immune response and in particular the innate immune system [5] and the health status of animals [6].

Most of the intensive housing and management systems used in commercial poultry farms have been developed in order to reduce the production cost and are not the best with respect to the ethological needs of animals. The welfare of laying hens raised in commercial cages has been placed under intense scrutiny. The housing of egg-type chickens in cages is now widely considered to have a negative effect on the welfare of hens [7-11]. Throughout Europe, concern for

*Address correspondence to this author at the Department of Applied Biology, Borgo XX giugno, 74 - 06121 Perugia, Italy; Tel: +390755857110; Fax: 390755857122; E-mail: dalbosco@unipg.it the welfare of laying hens in conventional cages has prompted changes in housing systems [12]. Cage-based systems are being phased out and those that are retained must meet high welfare standards [13]. The EC Directive 74/99 establishes the minimal requirements for hen protection and specifies new guidelines that provide for the progressive replacement of conventional cages that are to be completely eliminated by January 1, 2012 (European Commission, 1999). This directive stated that all existing cages must meet the $750 \mathrm{~cm}^{2} /$ bird space requirements and that each cage must be enriched with facilities that will allow birds to express their normal behaviours.

Among the different alternative farming systems organic egg production has increased during the last 15 years. In 2006, the market share in Italy of organically-produced eggs was $7.6 \%$ of all the organic products in retail and over a twoyear period the request for organic eggs increased by $4.6 \%$ [14].

To date, there has been no clear evidence that welfare is improved when hens are raised under the organic production system. Few studies have been published on this subject and the results are conflicting, due to the great variation in the 
breeds used, production methods, diets used, pasture availability. Some studies $[15,16]$ and review $[10,17]$ concerning the effect of conventional and free-range systems on productivity and product quality did not establish one system as being better than the other [18-23]. The overall main opinion is that successful organic farming will depend on the right combination of layout and management of the henhouse and free range on the one hand, and on the choice of the right breed of hen on the other, thus the balance between these aspects will probably be of major importance. Regarding the genotype of the hens to be used in order to assure a good welfare status, the EC Regulation 1804/99 and the final recommendation of Network for Animal Health and Welfare in Organic Agriculture (2003), suggest utilizing local breeds for their higher rusticity. Hybrid birds selected to produce under highly controlled conditions, seem to be quite unsuitable for extensive systems, such us the organic one because the environment is less controlled and the rations are less equilibrated. The use of less selected strains, which still conserve natural behaviours, could also be a valuable alternative, particularly if they are in danger of extinction [24]. Italy is the country of origin of some eggtype chicken strains that have seen a drastic decline in number; the Ancona breed which was widespread through Europe is an example. It has good productivity (about 280 eggs/year); the eggs are white and weigh 54-56 g [25]. As other pure breeds, Ancona has been progressively replaced by hybrids expressly selected for intensive egg production.

Being animal welfare a "state" [1] that encompasses many complex aspects of the animals it includes biological, psychological and ethical components. The biological components can be further divided into physical, physiological and behavioural. Most of the physical components of welfare are easy to determine, as it includes parameters traditionally used by the producers to evaluate performance and health. Behaviour is frequently used by experienced farmers to determine potential problems in animals [26] and the status of birds' integument has recognised of considerable impact on the interpretation of bird health and welfare [27, 28]. Physiological parameters which include hormone levels such as cortisol or corticosterone, heart rate or immune status [29-30] are frequently used as reliable indicators of the welfare status as well [31-33]. Moreover the haematological stress indicator $\mathrm{H} / \mathrm{L}$ is expected to increase if hens experience mild to moderate long-term stress [34]. Thus the aim of the present work was to compare the effect of organic production $v s$ standard cage system on welfare (through a multifunctional approach as behaviour, tonic immobility, feathers condition, antioxidant status of the body, blood parameters and innate immunity) and performance of a pure breed (Ancona) vs a commercial strain (Brown Hy-Line) of laying hens.

\section{MATERIAL AND METHODS}

\section{Animals, Housing and Feeding}

Five hundred 1-day-old chicks of the Ancona and two hundred 1-day-old female chicks of the Brown Hy-Line genotypes were reared during the first four weeks under identical conditions in floored pens, covered with wood shavings. The floored pens were located indoors in an environmentally-controlled building at the farm of the Dpt. of Applied Biology (University of Perugia). All animals were vaccinated against Marek and Newcastle diseases; the beaks were not trimmed and no other pharmacological treatments were given.

At 4-weeks-of-age, the Ancona females were divided in two homogenous groups of 100 birds each and the Brown Hy-Line were divided in two homogeneous groups, too. Two groups of them, the Control groups (Brown Hy-Line and Ancona; $\mathrm{CB}$ and $\mathrm{CA}$, respectively), were housed in cages, under standard rearing conditions (single bird cages, $0.75 \mathrm{~m}^{2}$ of three tier batteries that were provided with a linear automatic feeder and drinker; at 17 weeks-of-age an artificial photoperiod of $16 \mathrm{~h}$ per day of light was applied. The building was under a controlled ventilation regime (10 $\mathrm{m}^{3} / \mathrm{hen} / \mathrm{h}$ ), the temperature ranged from 15 to $29{ }^{\circ} \mathrm{C}$ (mean/average daily temperatures, winter 13-17, and summer, 23-35, extremes) and the relative humidity ranged from 50 to $80 \%$.

The lasts groups were transferred to a farm with building labeled for the requirements of the Council Directive 1999/74 and Directive 1804/99 regarding organic production. Both groups (Brown Hy-Line and Ancona; OB and $\mathrm{OA}$, respectively) were reared in two covered, strawbedded houses $\left(6 \mathrm{bird} / \mathrm{m}^{2}\right)$ with access to two pens with natural grazing $\left(10 \mathrm{~m}^{2} /\right.$ bird $)$. Feed and water were provided indoors with manual feeders and automatic drinkers respectively. Inside the paddocks, there was a small hut with nests ( 1 per 6 hens) and perches. Environmental temperature, humidity and photoperiod were the natural ones. A conveyor belt running along the back of the nests collected the eggs.

All the animals were reared according to Italian directives [35] on animal welfare for experimental and other scientific purposes along the year 2008.

A standard layer feed was given ad libitum to all groups; for organic groups more than $90 \%$ of the ingredients (maize, wheat and whole soybean) were organically grown. The nutritive characteristics of the feed were similar for all the groups: the main differences regarded the vitamins which, for organic groups, were in lower amount and coming from natural fonts; conventional diets had greater vitamin quantity of synthetic origin.

\section{Behavioural Observations}

Behavioural observations, Tonic Immobility Test (TI) and plumage evaluation were performed during four seasons, in a period of 5 days each. Ten animals per group were randomly selected and marked with different colours on the tip of the tail. Behavioural observations were recorded during three-hour periods in the morning (9.00-12.00) and afternoon (15.00-18.00) using the focal animal scan sampling method [36]. Before each observation session, 5 minutes were allowed for the animals to adapt to the presence of observers. The behavioural observations included: moving (walking, running and foraging), resting (standing, lying), feeding (food and water), comfort (dust bathing, self preening, scratching and starching), social relationships (allo-preening) and gentle and severe pecking others [37]. Behaviours were recorded on a custom-designed table, and their respective frequencies were calculated as a percentage of the total observed behaviours. Since no differences were found between days and hours, all data 
were pooled to obtain a mean value. At the end of behavioural observation birds were caught and submitted previous to the TI test [38] and then to plumage condition evaluation [28].

TI was induced by restraining the birds on their backs in a U-shaped wooden cradle for $10 \mathrm{~s}$ [38]. A bird was defined as being in a state of TI if it remained immobile for a minimum of $10 \mathrm{~s}$ after restraint had ended. A maximum of three inductions and a test ceiling of $3 \mathrm{~min}$ in TI were applied. The total duration of TI, i.e. until the bird righted itself, was recorded.

The plumage scoring system assigned values of 1 to 4 points for each trait [28], where a score of 4 implied the best and a score of 1 the worst condition. The 6 parameters (neck, breast, cloacae/vent, back, wings and tail) for plumage condition were summarized, implying a total score ranging from 6 to 24 points.

\section{Sample Collection and Analytical Determinations}

Blood samples for analyses were collected during four seasons, in all the different phases of the productive activity from the same ten birds after feather evaluation in the last day of behavioural observation. After collection from the brachial vein, blood samples were immediately sent to the laboratory where they were centrifuged and frozen at $-80{ }^{\circ} \mathrm{C}$ until analysis. Blood samples for hematocrite were collected in heparinized capillary tubes and centrifuged in a micro hematocrite centrifuge for $7 \mathrm{~min}$. Serum lysozyme was measured by a lyso-plate assay [39], carried out at $37{ }^{\circ} \mathrm{C}$ for 18 minutes, in a humidified incubator. The method is based on the lyses of Micrococcus lysodeikticus in 1\% agarose. The diameter of the lysed zones was measured with a ruler and was compared with the lysed zones of a standard lysozyme preparation (SIGMA, Milan, Italy, M 3770). The serum bactericidal activity (SBA) was performed according to a previous method validated for cattle [40]. The test is based on the challenge of sera with no pathogenic $E$. coli and its concentration was expressed in $\%$.

The haemolytic complement assay (HCA) [41] was carried out in microtitre plates. The complement titre is the reciprocal of the serum dilution causing $50 \%$ lyses of red blood cells of ram $\left(\mathrm{CH}_{50}\right)$.

Haptoglobin (Hp) was measured by a commercial kit (Phase Haptoglobin Colorimetric Assay, Tridelta Development Ltd, Kildare, Ireland) according to the manufacturer's directions. The test is based on the different peroxidase activity in acidic environment of haptoglobinhemoglobin complexes and free hemoglobin, respectively. Briefly, a known amount of hemoglobin is added at low $\mathrm{pH}$ to the serum sample; the residual peroxidase activity of hemoglobin is directly proportional to serum haptoglobin concentration.

Reactive oxygen species (ROS) and the Antioxidant Power of plasma (AP) of the sample were evaluated by a commercial kit (Diacron, Grosseto, Italy).

The leukocyte counts have been done on two drops of blood, and blood smears were made on duplicate glass slides. Both the slides were counted and the means were calculated for each bird. These smears were stained with Wright stain in $15 \mathrm{~min}$. One hundred leucocytes, including heterophils, lymphocytes, monocytes and eosinophils were counted on each slide. The $\mathrm{H} / \mathrm{L}$ ratio was also calculated.

\section{Productive Performance}

Data for calculating the \% of deposition, feed intake (FI) and bird mortality were recorded per cage/pen throughout the productive cycle by the farm workers. Feed consumption per cage/pen was recorded weekly. Mortality was recorded daily, while hen live weight (LW) was recorded at the end of the blood sampling.

\section{Statistical Analyses}

A linear model [42] was used to assess the effects of genotype and of rearing system and their interactions. For simplicity of exposition the season/age effect was not showed. Significance of the differences was assessed by the multiple t-tests and $X$-square was used for the nonparametric variables.

\section{RESULTS}

Generally, the genotype of the hens affected in a degree which depends on rearing system almost all the variables. Ancona breed was the responsible of such an interaction due the different response of the birds to the rearing system.

Behaviour of birds (Table 1). The feeding activity was higher in $\mathrm{CB}$ birds respect all other group, whereas resting activities were greater in CA birds, intermediate in $\mathrm{CB}$ and $\mathrm{OB}$ groups and lower in OA bird. Moving activities were higher in organic hens and especially in OA birds, while comfort activities were higher in $\mathrm{OB}$ and $\mathrm{CA}$ hens. Social relationships, in particular for allo-preening and gentle pecking behaviours, showed genotype and rearing system effects, showing Ancona hens the higher social relation ship percentage, whereas gentle/severe peaking were higher in Brown Hy-Line hens particularly when reared in cage; on the contrary OA showed the lowest value. It is important to underline that genotype did not affect the amount of severe pecking ( 0.5 vs $0.1 \%$, caged and organic hens, respectively) that occurs in close proximity of nests.

TI test and plumage conditions (Table 1). The TI time was affected by genotype and rearing system being the immobility time longer in Brown Hy-Line. Regarding Ancona hens the caged group showed the higher time of immobility. The plumage condition showed a great rearing system effect and genotype effect was observed only between organic groups where Ancona hens showed the better feathers condition.

Innate immunity and oxidative parameters (Table 2). SBA showed the highest values in organic hens and mainly in Ancona ones. On the contrary, lysozyme showed greater value in caged hens. The HP value was lower in OA group, whereas ROS were about $30 \%$ greater in organic hens. The highest AP value was shown by OA group.

Hematic parameters (Table 3). Organic rearing system, and within organic the Ancona hens, showed the highest red blood cells, haemoglobin and hematocrite values. Lymphocytes were higher in Organic birds thus reducing the $\mathrm{H} / \mathrm{L}$ ratio in Organic hens. Monocites and Eosinophils showed different trends: both groups of Ancona showed the 
Table 1. Effect of Genotype and Rearing System on Behavior, TI and Feather Condition in Laying Hens

\begin{tabular}{|c|c|c|c|c|c|c|}
\hline & & \multicolumn{2}{|c|}{ Brown Hy-Line } & \multicolumn{2}{|c|}{ Ancona } & \multirow{2}{*}{$X^{2}$} \\
\hline & & Control & Organic & Control & Organic & \\
\hline Feeding & $\%$ & $33.1^{\mathrm{b}}$ & $19.2^{\mathrm{a}}$ & $15.4^{\mathrm{a}}$ & $14.4^{\mathrm{a}}$ & 2.2 \\
\hline Resting & “ & $37.6^{\mathrm{b}}$ & $35.3^{\mathrm{b}}$ & $45.5^{\mathrm{c}}$ & $20.4^{\mathrm{a}}$ & 4.1 \\
\hline Moving & “ & $10.9^{\mathrm{a}}$ & $20.3^{b}$ & $13.8^{\mathrm{a}}$ & $47.7^{\mathrm{c}}$ & 3.5 \\
\hline Comfort & “ & $8.7^{\mathrm{a}}$ & $17.4^{\mathrm{bc}}$ & $19.2^{\mathrm{c}}$ & $14.1^{\mathrm{b}}$ & 2.4 \\
\hline Social relationships & “ & $0.9^{\mathrm{a}}$ & $1.0^{\mathrm{a}}$ & $3.6^{\mathrm{b}}$ & $3.0^{\mathrm{b}}$ & 0.5 \\
\hline Gentle/severe peaking & & $8.9^{\mathrm{d}}$ & $6.8^{\mathrm{c}}$ & $2.5^{\mathrm{b}}$ & $0.4^{\mathrm{a}}$ & 0.9 \\
\hline & & & & & & Pooled SE \\
\hline TI & s. & $127.5^{\mathrm{c}}$ & $156.3^{\mathrm{d}}$ & $93.8^{\mathrm{b}}$ & $32.5^{\mathrm{a}}$ & 21.2 \\
\hline Feather score & tot. & $15.9^{\mathrm{a}}$ & $17.5^{\mathrm{b}}$ & $16.5^{\mathrm{ab}}$ & $24.0^{\mathrm{c}}$ & 4.1 \\
\hline Neck & & $3.0^{\mathrm{a}}$ & $4.0^{\mathrm{b}}$ & $3.0^{\mathrm{a}}$ & $4.0^{\mathrm{b}}$ & 0.5 \\
\hline Breast & & $3.0^{\mathrm{a}}$ & $4.0^{\mathrm{b}}$ & $3.0^{\mathrm{a}}$ & $4.0^{\mathrm{b}}$ & 0.4 \\
\hline Cloaca/Vent & & $2.5^{\mathrm{a}}$ & $2.0^{\mathrm{a}}$ & $2.5^{\mathrm{a}}$ & $4.0^{\mathrm{b}}$ & 1.1 \\
\hline Back & & $3.0^{\mathrm{a}}$ & $3.0^{\mathrm{a}}$ & $3.0^{\mathrm{a}}$ & $4.0^{\mathrm{b}}$ & 0.7 \\
\hline Wing & & $2.2^{\mathrm{a}}$ & $2.5^{\mathrm{a}}$ & $2.5^{\mathrm{a}}$ & $4.0^{\mathrm{b}}$ & 0.4 \\
\hline Tail & & $2.2^{\mathrm{a}}$ & $2.0^{\mathrm{a}}$ & $2.5^{\mathrm{a}}$ & $4.0^{\mathrm{b}}$ & 0.5 \\
\hline
\end{tabular}

$\mathrm{N}=40$ per group (10 observed hens per 4 seasons); a..d: $\mathrm{P}<0,05$.

Table 2. Effect of Genotype and Rearing System on Innate Immunity and Oxidative Parameters in Laying Hens

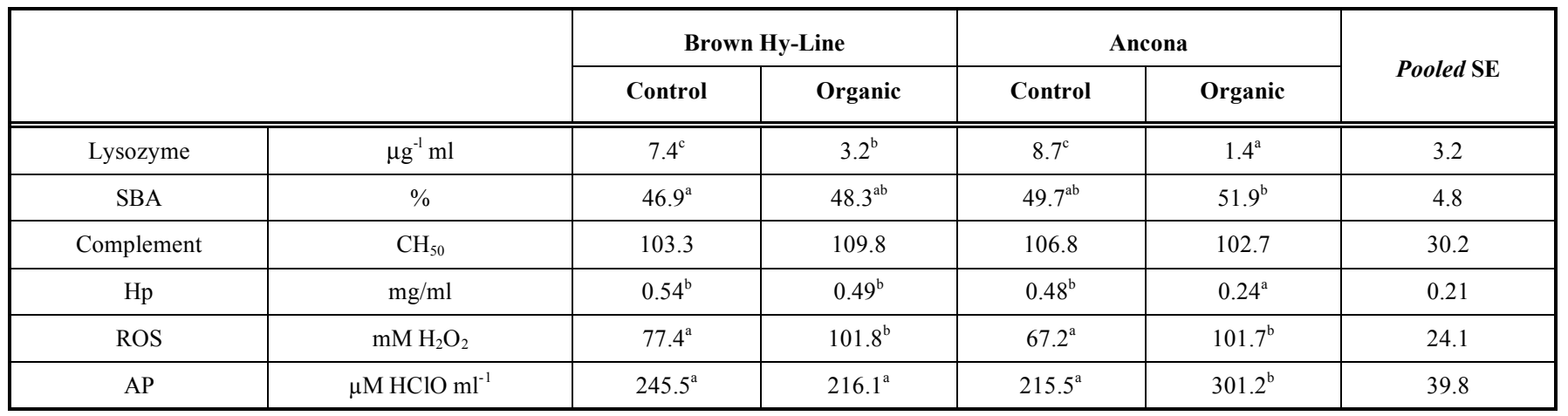

$\mathrm{n}=40$ per group (10 blood samples per 4 seasons); a..c: $\mathrm{P}<0,05$.

highest values of Monocites, while caged hens showed the highest values of Eosinophiles.

Productive traits (Table 4). As expected, OA hens showed the lower live weight and feed index. Organic birds showed the worst feed efficiency and percentage of deposition. Ancona birds showed a lower egg laid and lower number of marketable eggs (egg laid out nest and broken or cracked eggs). On the contrary, organic hens showed the lowest mortality rate.

\section{DISCUSSION}

For decades, animal breeding has focused on maximizing production traits. Such a selection pressure induces farm animals to allocate a large portion of their resources to a particular production trait, reducing their ability to respond to other demands (response to environmental stimuli, immunitary, etc). Accordingly, even the natural behaviour was affected. Indeed, selection for feed conversion efficiency (low residual food intake) has been found to be correlated with lower levels of activity compared to less efficient animals [43]. Our results confirm such assumption: selected hens had a higher feed and ME intake, which should compensate birds for an enhanced energy expenditure of higher egg production. On the same time Hy-lyne had greater percentage of resting behaviour also when reared in organic condition. On the contrary, Ancona hens, showed the lowest feeding efficiency and feed intake and, when the possibility was given, performed less resting at favour of kinetic (walking, running, foraging and exploring) activities. However, even the more productive strain positively respond to free range system: organic hens of both genotypes showed lower feeding and higher moving due to the given possibility of explore the environment and to forage. According to previous works [44] cage avoids the occurrence of some natural behaviours and animals supply to boredom through increasing their feeding activity. 
Table 3. Effect of Genotype and Rearing System on Hematic Parameters in Laying Hens

\begin{tabular}{|c|c|c|c|c|c|c|}
\hline & & \multicolumn{2}{|c|}{ Brown Hy-Line } & \multicolumn{2}{|c|}{ Ancona } & Pooled SE \\
\hline Hemoglobin & $\mathrm{g} / \mathrm{dl}$ & $14.9^{\mathrm{a}}$ & $14.5^{\mathrm{a}}$ & $14.0^{\mathrm{a}}$ & $16.5^{\mathrm{b}}$ & 4.15 \\
\hline Hematocrite & $\%$ & $30.1^{\mathrm{a}}$ & $31.7^{\mathrm{a}}$ & $28.8^{\mathrm{a}}$ & $34.2^{\mathrm{b}}$ & 7.24 \\
\hline Lymphocytes (L) & “ & $56.0^{\mathrm{a}}$ & $66.2^{\mathrm{b}}$ & $51.5^{\mathrm{a}}$ & $68.5^{\mathrm{b}}$ & 8.28 \\
\hline $\mathrm{H} / \mathrm{L}$ & & $0.65^{\mathrm{b}}$ & $0.45^{\mathrm{a}}$ & $0.75^{\mathrm{c}}$ & $0.39^{\mathrm{a}}$ & 3.15 \\
\hline Monocites & $\%$ & $3.6^{\mathrm{a}}$ & $6.0^{\mathrm{b}}$ & $6.4^{\mathrm{b}}$ & $5.8^{\mathrm{b}}$ & 3.15 \\
\hline Eosinofiles & “ & $4.0^{\mathrm{b}}$ & $2.0^{\mathrm{a}}$ & $3.6^{\mathrm{b}}$ & $1.5^{\mathrm{a}}$ & 0.98 \\
\hline
\end{tabular}

$\mathrm{n}=40$ per group ( 10 blood samples per 4 seasons); a..c: $\mathrm{P}<0,05$.

Table 4. Effect of Genotype and Rearing System on Some Productive Traits of Laying Hens

\begin{tabular}{|c|c|c|c|c|c|c|}
\hline & & \multicolumn{2}{|c|}{ Brown Hy-Line } & \multicolumn{2}{|c|}{ Ancona } & \multirow{2}{*}{ Pooled SE } \\
\hline & & Control & Organic & Control & Organic & \\
\hline Live weight* & $\mathrm{kg}$ & $2.07^{\mathrm{d}}$ & $1.96^{\mathrm{c}}$ & $1.89^{\mathrm{b}}$ & $1.69^{\mathrm{a}}$ & 0.09 \\
\hline Feed intake $^{\dagger}$ & $\mathrm{g} \mathrm{d}^{-1}$ & $121.4^{\mathrm{b}}$ & $120.6^{\mathrm{b}}$ & $110.6^{\mathrm{a}}$ & $114.0^{\mathrm{a}}$ & 6.0 \\
\hline \multicolumn{2}{|l|}{$\mathrm{ICA}^{* *}$} & $2.52^{\mathrm{a}}$ & $2.95^{\mathrm{b}}$ & $2.84^{\mathrm{b}}$ & $3.35^{\mathrm{c}}$ & 0.15 \\
\hline Egg deposition & $\%$ & $74.1^{\mathrm{b}}$ & $63.8^{\mathrm{a}}$ & $70.9^{\mathrm{b}}$ & $68.1^{\mathrm{b}}$ & 9.8 \\
\hline Egg laid & $\mathrm{g} \mathrm{d}^{-1}$ & $48.2^{\mathrm{c}}$ & $40.8^{\mathrm{b}}$ & $39.0^{\mathrm{b}}$ & $34.0^{\mathrm{a}}$ & 4.6 \\
\hline Egg laid out nest & $\%$ & - & 2.4 & - & 1.0 & 0.2 \\
\hline Broken or cracked eggs & “ & $0.5^{\mathrm{a}}$ & $2.7^{\mathrm{c}}$ & $1.1^{\mathrm{ab}}$ & $1.6^{\mathrm{ab}}$ & 0.4 \\
\hline Mortality*** & $\%$ & $4.3^{\mathrm{c}}$ & $2.5^{\mathrm{b}}$ & $4.1^{\mathrm{c}}$ & $1.6^{\mathrm{a}}$ & 0.7 \\
\hline
\end{tabular}

$*: \mathrm{N}=100$ per group; $* *$ : fed for egg $\operatorname{laid}^{-1} ; * * *: X^{2} ;$ a..b.: $\mathrm{P}<0,05$.

Tonic immobility evaluates fearful behaviour in the chicken [45] that represents a terminal defensive reaction and can be used as criterion for measuring the wellbeing and stress levels of the birds. Ancona hens organically reared gave the better response in term of tonic immobility and plumage condition. According to some Authors [46] that have reported that gentle pecking resembling a stereotypy, the higher rate of gentle pecking was found in caged hens. Regarding feathers conditions both the effects (genotype and housing condition) were significant; in fact it is largely documented that feather pecking is a multi-factorial problem affected by the genetic background of the birds [47-49] and group size and stocking density [50-52]. According to these Authors Brown Hy-Line hens performed the higher percentage of gentle pecking the other bird feathers that probably worsened their plumage condition. More over Brown Hy-Line hens are a typical commercial hybrid selected for egg production and Bestman and Wagenaar [53] described that some degree of feather pecking was seen in $71 \%$ of organic layer flocks of 50 weeks and older. They also described that the degree of feather pecking in flocks was less when more hens used the outdoor run as in the case of organic Ancona. These "behaviour" results can be interpreted as a greater welfare status in birds reared in more extensive conditions. Such hypothesis was confirmed by their better innate immunity and oxidative status evaluation mainly in pure breed.

Regarding innate immunity, lysozyme is a strong antibacterial enzyme (against $\mathrm{Gram}^{+}$) that has a synergic action with immune humoral response and factors of the serum complement [54]. It is essential related with the function of the macrophage system and basically indicates the presence of inflammation. SBA is a major parameter of innate immunity. The capacity of the serum to inhibit bacteria growth is assessed by the presence of complement factors and modulates the concentrations of natural antibodies against some more ubiquitous environmental bacterial agents, mainly Enterobacteriacee (Gram-). It gives same indications about the defence mechanisms of the animal that activates the complement system. The HCA is a test that shows the complement activity and is of great help in assessing the risk of infectious disease onset or the severity of already existing pathologies. Confirming behavioural results, AO hens showed better values for lysozyme and SBA. This hypothesis is confirmed by the lower value of HP; that is considered to bind free haemoglobin $(\mathrm{Hb})$ derived from inflammation processes in a stoichiometric ratio in vivo and in vitro. The resultant $\mathrm{HP}-\mathrm{Hb}$ complex is rapidly removed from the circulation by the reticuloendothelial system [55]. Moreover, these animals 
showed the higher moving and foraging activities and the consequent higher ROS haematic concentration, but accompanied by an increased haematic AP value that permitted to animal to adapt to the higher oxidative metabolism [56]. Oxidative stress, resulting from an increased production of free-radicals and ROS and/or a decrease in AP, makes damage to biological macromolecules and disturbs normal metabolism and physiology [57]. Oxygen free-radicals generated during biological processes are involved in the pathogenesis of several diseases and various reports have indicated that oxidative stress alters immune competence [58]. High level of ROS significantly reduces the primary and secondary antibody responses; further, the presence of sub-inflammatory process, evidenced by ROS and haptoglobin, enhances the lysozyme release by neutrophiles and macrophages and reduces the free complement which is mainly found in immuno-complexes.

Concerning haematic traits, heterophils increase and lymphocytes decrease when chickens are stressed, so that the ratio between them is a good index of response to a stressor. There is a genetic component to heterophils and lymphocytes responses to stressors [59]. Bayyari et al. [60] reported that lymphocyte numbers were lower in a line of turkeys selected for heavier BW than in a line selected for increased egg production. The differences for heterophils, lymphocytes, and the ratio between them observed in our experiment may be caused both by breed and housing. Gross and Siegel [61] suggested that reference values for the heterophil to lymphocyte ratio of about $0.2,0.5$, and 0.8 are characteristic of low, optimal, and high degrees of stress, respectively. On the basis of this affirmation organic hens showed $\mathrm{H} / \mathrm{L}$ values comprised between a low and optimal degrees of stress, on the contrary the caged ones showed values near a high degree of stress and between those the Ancona hens, being the more active suffered more of special constraining.

As previously affirmed, the question arises whether the selection for higher productivity affects the ability of animal to respond to environmental stressors. Responding to stress (i.e., adapting to a changing situation to maintain homeostasis) could be theoretically an energy demanding process. Many stressors that animals encounter are immunological challenges. Provided that having and activating an immune system is energetically costly [62,63], animals would have to make a trade off between immune response and maintaining production level. Being genetically programmed to efficient production, selected animals might have an impaired ability to make this trade-off, meaning that they are less capable to cope with an immune-related stress. According to this, beside an obvious genotype effect on the native immune and oxidative parameters analysed, less productive hens if requested to enhance their natural defence (OA) seem to be better adapted, probably linked to their lower productive performance that allowed to maintain their physiological homeostasis.

In conclusion, on the basis of all these information (greater AP response to ROS production, lower lysozyme, higher SBA, lower HP concentration, lower H/L) together with the low mortality rate it is possible to affirm that the Ancona hens showed the better welfare status, especially when they were organically reared.

\section{REFERENCES}

[1] Fraser AF, Broom DM. Welfare Measurement. In: Farm animal behaviour and welfare. CAB International. 1997; 266-79

[2] Yudkin JS, Kumari M, Humphries SE. Inflammation, obesity, stress and coronary heart disease: is interleukin-6 the link? Atherosclerosis 2000; 148: 209-14.

[3] Straub RH, Miller LE, Scholmerich J, Zietz B. Citokines and hormones as possible links between endocrinosenescence and immunosenescence. J Neuroimmunol 2000; 109: 10-5.

[4] Marchetti B, Morale MC, Testa N, et al. Stress, the immune system and vulnerability to degenerative disorders of central nervous system in transgenic mice expressing glucocorticoid receptors antisere RNA. Brain Res Rev 2001; 37: 259-72.

[5] Amadori M, Archetti IL, Frassinelli M, et al. An immunological approach to the evaluation of welfare in Holstein Frisian cattle. Istituto Zooprofilattico Sperimentale della Lombardia e dell'Emilia, Brescia, Italy 1997.

[6] Moscati L, Stelletta C, Sensi M, Sonaglia L, Battistacci L. Studio di alcuni parametri immunologici per la valutazione dello stato di benessere nell'allevamento del suino all'ingrasso. In: Proc. $V^{\circ}$ Congr. Naz. S.I.Di.L.V., Italy, 2003; pp. 103-4.

[7] Appleby MC. Should cages for laying hens be banned or modified? Anim Welf 1993; 2: 67-80.

[8] Appleby MC, Smith SF, Hughes BO. Nesting, dust bathing and perching by laying hens in cages: Effects of design on behaviour and welfare. Brit Poultry Sci 1993; 34: 835-47.

[9] Craig JV, Swanson JC. Review. Welfare perspectives on hens kept for egg production. Poultry Sci 1994; 73: 921-38.

[10] Van De Weerd H.A., Keatinge R, Roderick S. A review of key health-related welfare issues in organic poultry production. World Poultry Sci J 2009; 65, 649-84.

[11] Sossidou EN, Elson H.A. Hens' welfare to egg quality: a European perspective. World Poultry Sci J 2009; 65: 709-18.

[12] Savory CJ. Laying hen welfare standards: A classic case of "power to the people". Anim Welf 2004; 13: S153-S8.

[13] Keeling L, Svedberg J. Legislation banning conventional battery cages in Sweden and subsequent phase-out programme. Swedish University of Agricultural Sciences, Skara, Sweden 1999.

[14] ISMEA Bio, consumi frenati nel 2006, ISMEA - Ultime notizie 27 febbraio, Roma, Italy 2007. www.ismea.it/flex/cm/pages/ServeBL OB.php/L/IT/IDPagina/1099.

[15] Casagrande PP, Passamonti F, Asdrubali G. La gallina ovaiola allevata a terra e in gabbia. Rivista di Avicoltura 2001; 3: 12-5.

[16] Minelli G, Sirri F, Folegatti E, Meluzzi A, Franchini A. Egg quality traits of laying hens reared in organic and conventional systems. Ital J Anim Sci 2007; 6: 728-30.

[17] Berg C. Health and welfare in organic poultry production. Acta Veterinaria Scandinava 2001; 95: 37-45.

[18] Sauveur B. Mode d'élevage des poules et qualité de l'œuf de consommation. Production Animales 1991; 4: 123-30.

[19] Hovi M, Sundrum A, Thamsborg SM.. Animal health and welfare in organic livestock production in Europe: current state and future challenges. Livest Prod Sci 2003; 80: 41-53.

[20] Bestman M, Maurer V. Health and welfare in organic poultry in Europe: state of the art and future challenges. Proceedings of the Joint Organic Congress 'Organic Farming and European Rural Development' 2006; May 30-31, Odense, Denmark.

[21] Zeltner E, Maurer V. Welfare of organic poultry. World's Poultry Science Journal, Proc. $8^{\text {th }}$ European Symposium on Poultry Welfare, Cervia, Italy, 2009; 104.

[22] Ferrante V, Lolli S, Vezzoli G, Cavalchini LG. Effects of two different rearing systems (organic and barn) on production performance, animal welfare traits and egg quality characteristics in laying hens. Ital J Anim Sci 2009; 8: 165-74.

[23] Sundrum A. Organic livestock farming. A critical review. Livest Prod Sci 2001; 67: 207-15.

[24] Sponenberg DP, Christman C. A conservation breeding handbook. Ed. American Livestock Breeds Conservancy, Pittsboro, NC, USA, 1995.

[25] Castellini C, Panella F, Cavalletti C. Il recupero della razza Ancona: valutazione delle attitudini produttive. Rivista di Avicoltura 1990; 59: 47-50.

[26] Kjaer JB, Vestergaard KS. Development of feather pecking in relation to light intensity. Appl Anim Behav Sci 1999; 62: 243-254. Scott GB, Moran P. Fear levels in laying hens carried by hand and by mechanical conveyors. Appl Anim Behav Sci 1993; 36: 337-46. 
[28] Tauson R, Kjaer J, Maria G, Cepero R, Holm KE. Applied scoring of integument and health in laying hens. Anim Sci Pap Rep 2005; 23: $153-9$.

[29] Jones RB, Faure JM. Tonic immobility ("righting time") in laying hens housed in cages and pens. Appl Anim Ethol 1981; 7: 369-72.

[30] Craig, JV, Craig JA, Vargas JV. Corticosterone and other indicators of hen's well-being in four laying-house environments. Poultry Sci 1989; 65:856-63.

[31] Puvadolpirod S, Thaxton JP. Model of Physiological Stress in Chickens 1. Response Parameters. Poultry Sci 2000a; 79: 363-9.

[32] Puvadolpirod S, Thaxton JP. Model of physiological stress in chickens. 2. Dosimetry of adrenocorticotropin. Poultry Sci 2000b; 79: 370-6.

[33] Puvadolpirod S, Thaxton JP. Model of physiological stress in chickens. 3. Temporal patterns of response. Poultry Sci 2000c; 79: $377-82$.

[34] Maxwell, MH, Robertson, GW. The avian heterophil leucocyte: a review. World Poultry Sci J 1998; 54; 155-78.

[35] Gazzetta Ufficiale, 1992. Attuazione della Direttiva 86/609/CEE in materia di protezione degli animali utilizzati ai fini sperimentali o ad altri fini scientifici, D.L. January 27, 1992, n. 116. In: Supplemento ordinario alla Gazzetta Ufficiale, n. 40, 1992; 1-12.

[36] Martin P, Bateson P. Measuring behaviour. An introductory guide. By. New York: Cambridge University Press 1986.

[37] Kjaer JB, Sørensen P. Feather pecking behaviour in White Leghorns, a genetic study. Brit Poult Sci 1997; 38, 333-41.

[38] Gallup GG. Tonic immobility as a measure of fear in domestic fowl. Anim Behav 1979; 27: 316-7.

[39] Osserman EF, Lawlor DP. Serum and urinary lysozyme (muramidase) in monocytic and monomyelocitic leukemia. J Exp Med 1966; 124: 921-52.

[40] Amadori M, Archetti IL, Frassinelli M, et al. An immunological approach to the evaluation of welfare in Holstein Frisian cattle. Ist Zoopr Sper Brescia 1997.

[41] Barta V, Barta O. Testing of Hemolitic Complement and its components. Vet. Cl. Imm. Lab., Bar-Lab, Blacksburg, USA, 1993.

[42] StataCorp. Stata Statistical Software: Release 9. College Station, TX: StataCorp.LP, 2005.

[43] Dunnington EA. Selection and homeostasis. In: Proceedings $4^{\text {th }}$ World Congress on Genetics Applied to Livestock Production XVI. Edinburgh, Scotland 1990; pp. 5-12.

[44] Castellini C, Perella F, Mugnai C, Dal Bosco A. Welfare, productivity and qualitative traits of egg in laying hens reared under different rearing systems. In Proc. European Poultry Conference: Verona, Italy 2006.

[45] Bessei W. Untersuchungen zur Heritabilität des Federpickverhaltens bei Junghennen. I. Mitteilung. Archiv für Geflügelkunde 1984; 48: 224-31.

[46] Rodenburg TB, Buitenhuis AJ, Ask B, et al. Heritability of feather pecking and open-field response in laying hens at two different ages. Poultry Sci 2003; 82, 861-7.

[47] Nicol CJ, Gregory NG, Knowles TG, Parkman ID, Wilkins LJ. Differential effects of increased stocking density, mediated by increased flock size, on feather pecking and aggression in laying hens. Appl Anim Behav Sci 1999; 65: 137-52.

[48] Braastad BO, Katle J. Behavioural differences between laying populations selected for high and low efficiency of food utilisation. Brit Poultry Sci 1989; 30:533-44.

[49] Bilcı'k B, Keeling LJ. Relationship between feather pecking and ground pecking in laying hens and the effect of group size. Appl Anim Behav Sci 2000; 68, 55-66.

[50] Rodenburg TB, Koene P. The impact of group size on damaging behaviours, aggression, fear and stress in farm animals. Appl Anim Behav Sci 2007; 103: 205-14.

[51] Estevez I., Keeling L., Newberry R.C. 2003. Decreasing aggression with increasing group size in young domestic fowl. Appl Anim Behav Sci 2003; 3:213-8.

[52] Ferrante V., Lolli S., Vezzoli G., Cavalchini L.G. Effects of two different rearing systems (organic and barn) on production performance, animal welfare traits and egg quality characteristics in laying hens. Ital J Anim Sci 2009; 8: 165-74.

[53] Bestman J, Wagenaar JP. Farm level factors associated with feather pecking in organic laying hens. Livest Prod Sci 2003; 80: 133-140.

[54] Carroll SF, Martinez RJ. Role of rabbit lysozyme in in vitro serum and plasma serum bactericidal reactions against Bacillus subtilis. Infect Immunol 1979; 25: 810-9.

[55] Giblet E. Haptoglobin. In: A.C. Allison, Editor, Structure and Function of Plasma Proteins, Plenum, New York 1974; 55-72.

[56] Alessio HM, Hagerman AE, Fulkerson BK, Ambrose J, Rice RE, Wiley RL. Generation of reactive oxygen species after exhaustive aerobic and isometric exercise. Med Sci Sports Exerc 2000; 32: 1578-81.

[57] Tse HM, Milton MJ, Piganelli JD. Mechanistic analysis of the immunomodulatory effects of a catalytic antioxidant on antigenpresenting cells: implication for their use in targeting oxidationreduction reactions in innate immunity. Free Radical Biol Med 2004; 36: 233-47.

[58] Koner BC, Banerjee BD, Ray A,. Effects of in vivo generation of oxygen free radicals on immune responsiveness in rabbits. Immunol Lett 1997; 59: 127-31.

[59] Campo JL, Prieto MT, Dávila SG. Effects of housing system and cold stress on heterophil-to-lymphocyte ratio, fluctuating asymmetry, and tonic immobility duration of chickens. Poultry Sci 2008; 87: 621-6.

[60] Bayyari VE, Huff WE, Rath NC, et al. Effect of the genetic selection of turkeys for increased body weight and egg production on immune and physiological responses. Poultry Sci 1997; 76: 28996.

[61] Gross WB, Siegel HS. Evaluation of the heterophil/lymphocyte ratio as a measure of stress in chickens. Avian Disease 1983; 27 972-9.

[62] Verhulst S, Dieleman S.J, Parmentier H.K. A tradeoff between immunocompetence and sexual ornamentation in domestic fowl Proc Natl Acad Sci USA. 1999; 96: 4478-81.

[63] Lochmiller R.L, Deerenberg C. Trade-offs in evolutionary immunology: just what is the cost of immunity? Oikos 2000; 88 : $87-98$. 